Embryonic suckling and maternal specializations in the live-bearing teleost Zoarces viviparus

Skov, Peter Vilhelm; Steffensen, John Fleng; Sorensen, Thomas Flarup; Qvortrup, Klaus

Published in:

Journal of Experimental Marine Biology and Ecology

DOI:

10.1016/j.jembe.2010.08.024

Publication date:

2010

Document version

Early version, also known as pre-print

Citation for published version (APA):

Skov, P. V., Steffensen, J. F., Sorensen, T. F., \& Qvortrup, K. (2010). Embryonic suckling and maternal specializations in the live-bearing teleost Zoarces viviparus. Journal of Experimental Marine Biology and Ecology, 395(1-2), 120-127. https://doi.org/10.1016/j.jembe.2010.08.024 


\title{
Embryonic suckling and maternal specializations in the live-bearing teleost Zoarces viviparus
}

\author{
Peter Vilhelm Skov ${ }^{\mathrm{a}, *}$, John Fleng Steffensen ${ }^{\mathrm{a}}$, Thomas Flarup Sørensen ${ }^{\mathrm{b}}$, Klaus Qvortrup ${ }^{\mathrm{c}}$ \\ ${ }^{a}$ Marine Biological Laboratory, University of Copenhagen, DK-3000 Helsingør, Denmark \\ ${ }^{\mathrm{b}}$ Department of Science, Systems and Models, Roskilde University, DK-4000 Roskilde, Denmark \\ c Department of Biomedical Sciences, University of Copenhagen, DK-2200 Copenhagen, Denmark
}

\section{A R T I C L E I N F O}

\section{Article history:}

Received 25 March 2010

Received in revised form 20 August 2010

Accepted 23 August 2010

\section{Keywords:}

Matrotrophy

Nutrition

Oxygen

Suckling

Viviparity

\begin{abstract}
A B S T R A C T
The European eelpout follows an aplacental viviparous reproductive strategy, in which gestation lasts 45 months. During the last months of development yolk reserves are depleted, and embryos depend on an external source of nutrients. Here we provide evidence for novel specialized physiological, morphological and behavioural adaptations, which we propose as the responsible mechanisms for the exchange of nutrients and gases between the maternal organism and her embryos. Ovarian follicles contain an internal glomeruluslike structure within the distal tip of each follicle. Ultrastructural examination indicated a capacity for steroid synthesis and secretion. Gel electrophoresis demonstrated a protein size distribution in the follicular fluid different from that of the maternal serum, and that ovarian fluid is devoid of protein. From vascular casts and histological sections the follicle was reconstructed. The glomerulus has a central canal that is exteriorized at the tip of the follicle, allowing passage of follicular fluid. Oxygen measurements across the ovary of nearterm females showed a strongly hypoxic ovary lumen, yet ovarian fluid adjacent to follicles was oxygen saturated. As another novel observation, embryos were seen engaged in suckling on follicles. We hypothesize that embryos use the follicles on the ovarian wall as placental analogues and that they use their mobile jaw apparatus to attach themselves and apply suction.
\end{abstract}

(C) 2010 Elsevier B.V. All rights reserved.

\section{Introduction}

The course of embryonic development in the European eelpout, Zoarces viviparus (Linnaeus, 1758), has been described in detail (Soin, 1968; Kristoffersson et al., 1973; Korsgaard and Andersen, 1985; Rasmussen et al., 2006). In brief, the female reproductive cycle is initiated by the simultaneous maturation of 25-400 oocytes in the ovarian wall (Soin, 1968; Rasmussen et al., 2006). Each oocyte has its own vascular supply in the form of follicles that grow during maturation and project perpendicularly into the ovary lumen. During ovulation, a single mature oocyte is released by each follicle into the lumen of the ovary, and follicles do not undergo atresia during the subsequent development of embryos.

Gestation in the eelpout lasts 18-22 weeks. Eggs hatch 3 weeks after fertilization and the developing embryos deplete their yolk sac reserves during the following 6 weeks (Rasmussen et al., 2006). For the remaining 9-13 weeks until parturition, embryos have a wet mass gain of more than 1500\% (Kristoffersson et al., 1973; Korsgaard and Andersen, 1985), and must depend on an external nutritional source. As extra-vitelline sources must account for some $90 \%$ of the wet mass

\footnotetext{
* Corresponding author. DTU Aqua, Technical University of Denmark, DK-9850 Hirtshals, Denmark. Tel.: +453588 3263; fax: +45 35883260 .

E-mail address: pvsk@aqua.dtu.dk (P.V. Skov).
}

of near-term embryos, several hypothesis have been put forward as to how Z. viviparus provides nutrition for their young. Soin (1968) described the development of a mobile jaw apparatus early in the embryonic development, which for some time was considered a mechanism to facilitate ingestion of ovarian fluid, the uptake of which is facilitated by a hypertrophied hind gut (Kristoffersson et al., 1973). Nutritive substances in the ovarian fluid were thought to originate from a fatty mucous fluid secreted by the ovary wall (Stuhlmann, 1887). However, as no nutritional components have been found in the ovarian fluid (Kristoffersson et al., 1973; Korsgaard, 1983) this scenario appears unlikely.

In contrast, the fluid within the follicle has been shown to be rich in protein, free fatty acid and glucose, with levels identical to that of maternal serum (Korsgaard, 1983). Because the follicle is a closed structure, these nutritional substances are not readily available to developing embryos, and various proposals have been made as to which mechanisms might facilitate transepithelial passage (Skov et al., 2007).

Further to uncertainties pertaining embryonic nutrition, there is the question of oxygen delivery to the embryos. Embryos of $Z$. viviparus lie freely suspended in the ovarian fluid with no direct maternal connection or specialized structures to facilitate oxygen uptake. Oxygen content in the ovarian fluid of $Z$. viviparus is low, with a $\mathrm{PO}_{2}$ of less than $5 \mathrm{kPa}$ (Hartvig and Weber, 1984). Despite a high 
oxygen affinity in embryonic whole-blood, with a half-saturation tension of $1.2 \mathrm{kPa} \mathrm{PO}_{2}$ (Hartvig and Weber, 1984), embryonic development in a hypoxic environment cannot be unproblematic. Among viviparous fishes, embryos typically have specialized structures to facilitate maternal-embryonic exchange, in the form of external portal networks, trophotaeniae (external outgrowths of the gut) or vascularized enlarged fin folds (Balon, 1975; Turner, 1947; Webb and Brett, 1972). In some viviparous poeciliid species, maternal specializations in the form of vascularized ovarian skin-folds, "grow into the opercular opening' of the embryo (Turner, 1947). These structures may be solely for gas transfer or gas and nutrient transfer (Jollie and Jollie, 1964), during what is a comparatively short gestation time ( 3-4 weeks).

The present work was spurred on by observations made during dissection of a fixed near-term pregnant female, in which several embryos had an ovarian follicle within the oral cavity. The aim of the study was to investigate any morphological and physiological adaptations to facilitate maternal-embryonic exchange of oxygen and nutrients to developing embryos in $Z$. viviparus. Using vascular casts, histology and electron microscopy we reconstructed the internal follicular structure, to identify possible pathways for nutritional transfer and ultra structural specializations. In order to provide an estimate of the metabolic costs associated with pregnancy we used respirometry to determine resting metabolic rate of nonreproductive males and near-term pregnant females.

\section{Materials and methods}

\subsection{Animals}

European eelpout, Z. viviparus were caught locally in set eel traps from October to November. Animals were kept in 4501 aerated holding tanks at the Marine Biological Laboratory, University of Copenhagen, according to Danish institutional guidelines for animal research. Holding tanks were continuously supplied $\left(81 \mathrm{~min}^{-1}\right)$ with $10{ }^{\circ} \mathrm{C}$ recirculating filtered seawater (30 ppt.) and kept under a $12 \mathrm{~h}$ light: $12 \mathrm{~h}$ dark regime. Fish were fed to apparent satiation twice weekly with chopped mussels (Mytilus edulis). All experiments were performed from mid December to late January.

\subsection{Respirometry}

Oxygen consumption studies were performed using computerized intermittent flow respirometry (Steffensen, 1989) using a Fibox oxygen meter and dipping probe (Loligo Systems, Denmark). Measurements were made on females during the last month of pregnancy (mean mass \pm S.E. $81.9 \pm 13.7 \mathrm{~g}, N=10$ ) and non-reproductive males $(66.9 \pm 5.5 \mathrm{~g}, N=10)$ in a 1.4481 shielded respirometer. Animals were allowed to recover from handling overnight in the respirometer prior to measurements. To enable comparison of oxygen consumption in different sized fishes measurements were corrected to a body mass of $100 \mathrm{~g}$ (Steffensen et al., 1994) using the equation $\mathrm{VO}_{2(100)}=\mathrm{VO}_{2(\mathrm{BM})} \times(\mathrm{BM} / 100)^{(1-\mathrm{A})}$, where $\mathrm{VO}_{2(\mathrm{BM})}$ is the oxygen consumption of an animal with a body mass BM and $\mathrm{A}$ is the mass exponent describing the relationship between metabolic rate and oxygen consumption. In the present study the commonly used exponent of 0.8 was used.

\subsection{Ovarian oxygen availability}

Profiles of the oxygen tension across the ovary lumen were made using a Microx oxygen sensor with a needle-type fibre optic oxygen sensor (Precision Sensing GmBH, Regensburg, Germany). Fish were anaesthetized with Benzocaine $\left(0.06 \mathrm{gl}^{-1}\right)$, placed on their side, nearly submersed on a foam rubber mat, and ventilated with fully aerated seawater containing anaesthetic $\left(0.03 \mathrm{~g} \mathrm{l}^{-1}\right)$. A small lateral incision was made to access the ovary at its widest point, the ovary wall was punctured and the oxygen sensor advanced to the opposing ovary wall. Using a micromanipulator, the oxygen sensor was retracted $1 \mathrm{~mm}$ at a time and the partial pressure of oxygen recorded. Distances across the ovary varied from 32 to $38 \mathrm{~mm}$. Measurement points were transformed to percentage of distance across the ovary and binned to the nearest $5 \%$ interval. Subsequently oxygen pressures were measured adjacent to the tip of 3 follicles from each individual. Animals were killed by spinal transection, the embryos were removed, counted, and weighed.

\subsection{Gel electrophoresis}

The size distribution of proteins in female serum, ovarian fluid and follicular fluid from 2 late term pregnant females was analysed by SDS-PAGE using a NuPAGE system (Invitrogen, Denmark). Female serum was obtained from the caudal vein, while ovarian fluid was obtained by Pasteur pipettes after the ovaries were dissected out. Fluid from the follicles was obtained using $10 \mu \mathrm{l}$ capillary tubes and pooled into $0.2 \mathrm{ml}$ Eppendorf tubes. A 10\% BIS-TRIS gel with MES running buffer was used (Invitrogen) with a Mark12 unstained standard (2.5-200 kDa) (Invitrogen). Female serum and follicular fluid were diluted 10 -fold, while ovarian samples were diluted 2 -fold prior to loading. A $15 \mu \mathrm{l}$ sample was loaded onto individual lanes and the gel was run at fixed voltage $(200 \mathrm{~V})$ for $60 \mathrm{~min}$ before being stained in Coomassie Blue R-250 for 45 min and destained overnight in $10 \%$ acetic acid / $30 \%$ methanol.

\subsection{Vascular casting}

Vascular casting was performed as described previously (Skov and Bennett, 2004). In brief, animals were euthanized in an overdose of Benzocaine $\left(0.15 \mathrm{~g} \mathrm{~L}^{-1}\right)$, before the ventral aorta was cannulated normograde via the heart. The animal was cleared of blood with 40$60 \mathrm{ml}$ of $1.0 \% \mathrm{NaCl}\left(\mathrm{pH} \mathrm{7.8)}\right.$ containing Heparin $\left(20 \mathrm{IU} \mathrm{ml}^{-1}\right)$ and sodium nitroprusside $(10 \mu \mathrm{M})$. A polyurethane resin (vasQtec, Zurich, Switzerland) diluted 4:3 with ethyl methyl ketone was injected into the vascular system and allowed to polymerize overnight before digesting the entire animal in several changes of $20 \%$ (w:v) $\mathrm{KOH}$.

\subsection{Scanning electron microscopy}

Relevant pieces of vascular cast were dissected free and mounted on aluminium stubs using double-sided carbon tape, platinum coated and viewed in a field emission scanning electron microscope (JEOL JSM-6335F, Tokyo, Japan). Tissues for SEM were dehydrated in a graded series of ethanol, and then transferred to $100 \%$ hexamethyldisilazane (HMDS) (Braet et al., 1997) in a volume sufficient to cover the specimen. HMDS was allowed to evaporate in the fume-hood, mounted and coated as above.

\subsection{Histology}

Animals were cannulated as described above and flushed with saline, and perfusion fixed with $2 \%$ paraformaldehyde (PFA) in $0.1 \mathrm{M}$ phosphate buffered saline (PBS). Ovaries were dissected out and postfixed in $4 \%$ PFA in $0.1 \mathrm{M}$ PBS at $4{ }^{\circ} \mathrm{C}$ overnight. Follicles were dissected out and dehydrated in a graded series of ethanol, infiltrated and embedded in blocks of Technovit 7100 (Heraeus Kulzer GmbH, Wehrheim, Germany) at $4{ }^{\circ} \mathrm{C}$. Blocks were sectioned to distilled water at $3 \mu \mathrm{m}$ and dried on a hotplate at $60{ }^{\circ} \mathrm{C}$ until well bonded, stained with $\mathrm{H} \& \mathrm{E}$, rinsed in distilled water, air dried and cover slipped using DPX. 


\subsection{Transmission electron microscopy}

Fish were perfusion fixed as described above, using $2.5 \%$ glutaraldehyde in $0.1 \mathrm{M}$ PBS. Ovaries were removed and stored in $2.5 \%$ glutaraldehyde in $0.1 \mathrm{M}$ PBS at $4{ }^{\circ} \mathrm{C}$ until processed for transmission electron microscopy (TEM). Suitable specimen samples were rinsed three times in $0.15 \mathrm{M}$ sodium cacodylate buffer ( $\mathrm{pH} 7.2$ ) and subsequently post-fixed in $1 \%$ OsO4 in $0.12 \mathrm{M}$ sodium cacodylate buffer ( $\mathrm{pH}$ 7.2) for $2 \mathrm{~h}$. The specimens were dehydrated in a graded series of ethanol, transferred to propylene oxide, and embedded in Epon according to standard procedures. Ultrathin sections were cut with a Reichert-Jung Ultracut E microtome and collected on 200-mesh copper grids with Formvar supporting membranes. The sections were stained with uranyl acetate and lead citrate and examined with a Philips CM 100 transmission electron microscope, operated at an accelerating voltage of $80 \mathrm{kV}$.

\section{Results}

\subsection{Energetic costs of gestation and oxygen availability}

The relationship between length and mass of 10 near-term females and 20 non-reproductive males was best described by non-linear regressions (Fig. 1A).

$$
\begin{aligned}
& \text { Female BM }=7.01 \times 10^{-6} \times S L^{2.98}\left(R^{2}=0.96\right) \\
& \text { Male BM }=3.59 \times 10^{-6} \times S L^{2.63}\left(R^{2}=0.83\right)
\end{aligned}
$$

where BM is body mass in grams and SL is standard length in $\mathrm{mm}$. Gestating females were significantly heavier than males of similar length (One way ANOVA, $P<0.05$ ). The difference between Eqs. (1) and (2) is the mass increase during gestation (GMI) of a near-term female at a given standard length (SL)

$G M I=2.18 \times 10^{-8} \times S L^{3.80}$

Animal mass, intact ovarian mass, and embryonic mass was determined from 4 near-term females. The intact ovary accounted for $28.4 \pm 1.5 \%$ of the pregnant mass, of which $69.6 \pm 1.4 \%$ was embryos, approximately $10 \%$ was ovarian fluid and the remaining $20 \%$ was ovarian tissue.

Metabolic rates increased with body mass for both males and females. Females had a significantly (t-test, $P<0.001)$ higher SMR $(31.5 \pm$ $\left.1.6 \mathrm{mg} \mathrm{O}_{2} \mathrm{~kg}^{-1} \mathrm{~h}^{-1}, \mathrm{~N}=10\right)$ than males $\left(23.9 \pm 0.9 \mathrm{mg} \mathrm{O}_{2} \mathrm{~kg}^{-1} \mathrm{~h}^{-1}\right.$, $N=10)$. The correlation between oxygen consumption $\left(\mathrm{mg} \mathrm{O}_{2} \mathrm{~h}^{-1}\right)$ and body mass was found to be

$$
\begin{aligned}
& \text { Female } \mathrm{MO}_{2}=0.0313 \times \mathrm{BM}^{1.01}\left(R^{2}=0.95\right) \\
& \text { Male } \mathrm{MO}_{2}=0.0366 \times B M^{0.92}\left(R^{2}=0.85\right) .
\end{aligned}
$$

Transverse ovarian oxygen profiles showed that the centre of the ovary was nearly anoxic $\left(\mathrm{PO}_{2}<1 \mathrm{kPa}\right)$, while conditions close to the ovary wall were close to normoxic $\left(\mathrm{PO}_{2}\right.$ between $\left.8.6-16.8 \mathrm{kPa}\right)$. Adjacent to the tip of the follicle ovarian fluid was fully oxygenated $\left(\mathrm{PO}_{2} 21.87 \pm 0.96 \mathrm{kPa}, \mathrm{N}=4\right)$ (Fig. 1B).

\subsection{Follicular anatomy}

The gross organization of ovarian blood vessels and capillary organization of the follicles was described previously (Skov et al., 2007) using traditional acrylic casting agents. Acrylic resins cannot be dissected due to their brittle nature. The present study used
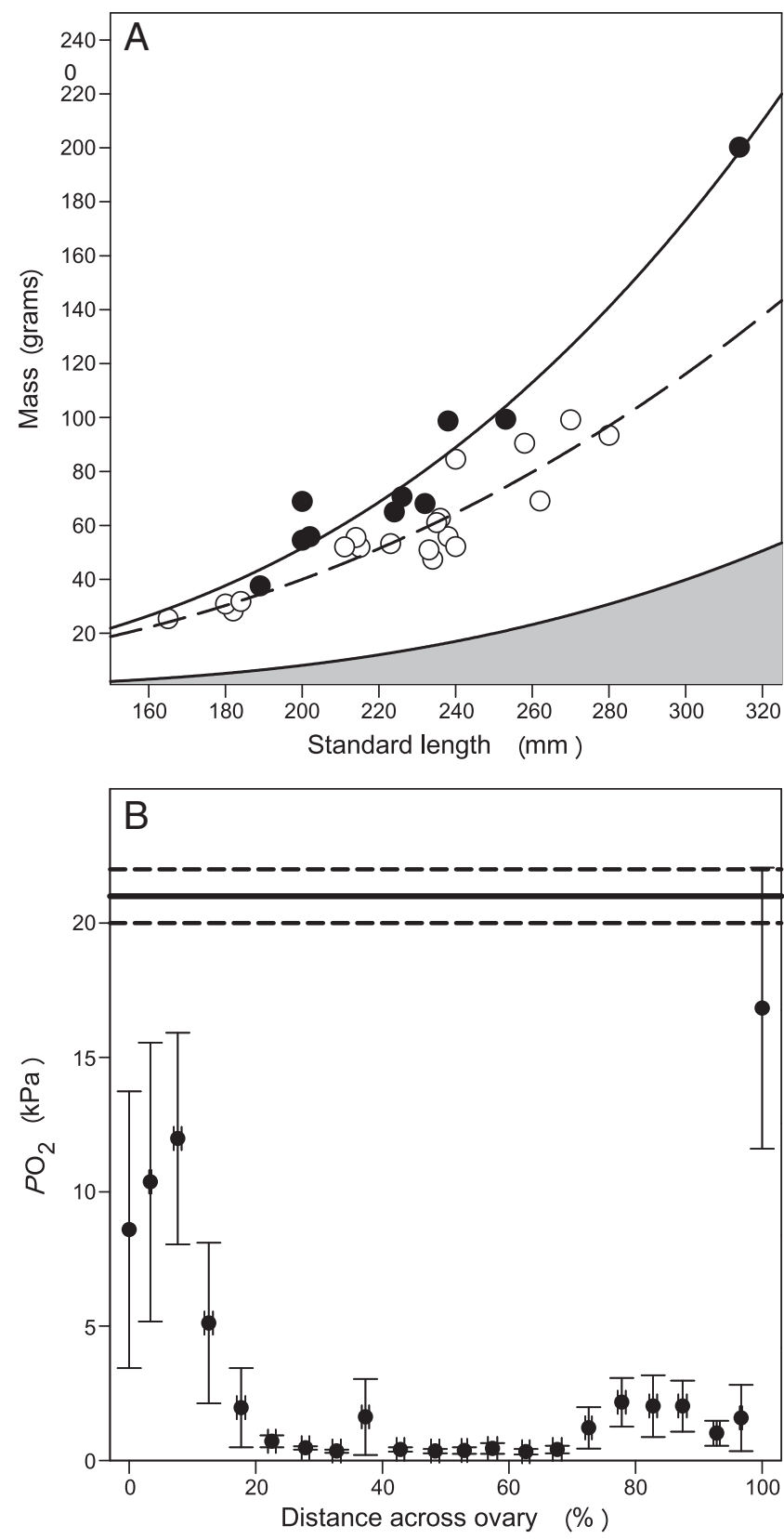

Fig. 1. (A) The relationship between standard length and body mass of nonreproductive males (open circles, stippled line) and near-term females (filled circles, solid line). The difference describes the gestational mass increase (Eq. (3)) of which 70\% is accounted for by embryonic mass. The calculated embryonic mass of a near-term pregnant female of a given length is illustrated by the hatched area. (B) Partial pressure of oxygen $\left(\mathrm{PO}_{2}\right)$ across the ovary of 4 near-term females. Values are mean \pm standard error of the mean. The solid horizontal line represents mean values measured adjacent to the tip of 3 follicles from 4 individuals, with stippled lines denoting standard error of the mean.

polyurethane resin which allowed for micro-dissection of vascular casts. In combination with histological approaches, we were able to obtain novel information on the anatomy of the internal structure of the follicles. A semi-schematic representation of the internal follicular anatomy is given in Fig. 2. Follicles vary in length, between $8-12 \mathrm{~mm}$. At the base, the follicle is supplied by a single central blood vessel from the ovary wall. Approximately one-third along the length of the follicle, the supplying vessel divides repeatedly into half a dozen smaller vessels which continue their course for a few millimeters before giving rise to a tuft of convoluted capillaries near the tip of the 


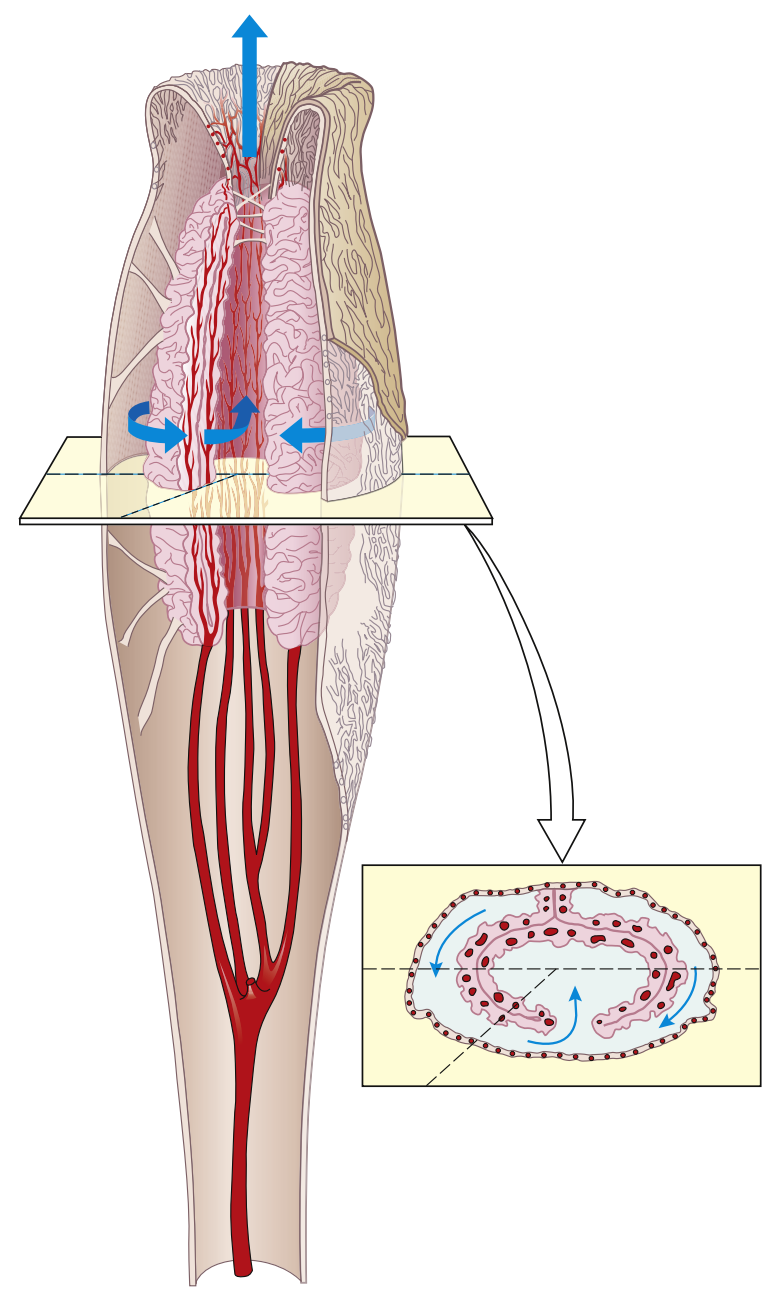

Fig. 2. A semi-schematic representation of the morphology of a follicle from a near-term female. Arterial supply originates from a single vessel which divides repeatedly to supply the vessels of the glomerulus-like structure suspended by strands of connective tissue at the tip of the follicle. Blood vessels are partially filled with red to illustrate blood flow from the arterial supply, through the divided vessel system to the glomerulus and from here to the external capillary layer. Blue arrows indicate movement of follicular fluid. A section of the follicle containing part of the glomeruluslike structure, parts of the external capillaries and the epithelial layer have been removed for clarity. Inset provides an intact transverse view of the structure. For details see also Fig. 3.

follicle (Fig. 3C-D). This vascular structure resembles a glomerulus with some modifications; it is oval in shape and approximately 4$5 \mathrm{~mm}$ in length and $2-3 \mathrm{~mm}$ at its widest point. From histological sections and SEM images of dried tissue, it is apparent that the glomerulus is enclosed by an epithelial layer (Fig. 3E). The glomerulus is made up by a bi-layer of blood vessels on either side of a layer of connective tissue which is folded onto itself on the longitudinal axis, forming an elongate horseshoe shaped structure (Fig. 3A). The external base of this fold is fused to the inside of the follicular wall (Fig. 2, inset; Fig. 3A) and maintained in place by projections of connective tissue from the outer epithelial layer of the glomerulus to the endothelial lining of the follicle (Fig. 2). The fold created by these vessels forms a central lumen within the glomerulus, termed the glomerular space. Because of the horseshoe shape of this structure and the way it is suspended within the follicle, the fluid in the glomerular space stands is in open connection with the fluid in the surrounding follicular space. From the distal part of the glomerulus a network of capillaries originate from the cone-shaped depression at the tip and make a full turn to envelop the entire follicular structure
(Figs. 2 and 3B). At the base of the follicle, these capillaries continue their course across the ovary wall and eventually drain into venous return vessels spread across the ovary wall.

\subsection{Glomerular ultrastructure}

The lumen of the blood vessels within the glomerulus ranged between $20-30 \mu \mathrm{m}$ in diameter (Fig. 4A). The wall is composed of a layer of endothelial cells lined by a continuous layer of pericyte like cells (Fig. 4B,F,G). The endothelial cells are joined by tight junctions (Fig. 4G). In the luminal plasmalemma several invaginations, of which some are coated, could be observed, while the plasmalemma towards the pericytes often showed numerous caveolae (Fig. 4F). The endothelial cells contain mitochondria, Golgi complexes, rough endoplasmic reticulum and dense granula (Fig. 4C,D). Pericytes contained fewer organelles than the endothelial cells, but dense granula could also be observed in these cells (Fig. 4A,B). A thin layer of connective tissue with sparse collagen fibres separates the vessels from a mesangial-like core of the network (Fig. 4C), while the cells in the core are joined by desmosomes (Fig. $4 \mathrm{H}$ ). The cells contain numerous mitochondria with tubular cristae, rough endoplasmic reticulum and Golgi complexes (Fig. 4G). In some of the cells an abundance of dense granula with a diameter of 3-400 $\mathrm{nm}$ could be observed (Fig. 4A,B). Interspersed between the cells smooth muscle cells could be seen (Fig. 4E).

\subsection{Gel electrophoresis}

The electrophoretic gel showed that the ovarian fluid was practically devoid of any protein with only a few weak bands occurring around the $14.4 \mathrm{kDa}$ marker (Fig. 5). Only 6-7 distinct bands were seen in the adult serum. Distinct protein bands were more numerous in the follicular fluid, several of which corresponded to molecular weights not seen in adult serum.

\subsection{Behavioural adaptations}

As mentioned in the Introduction, the present study was undertaken following the careful dissection of a single immersion fixed pregnant female which revealed for the first time that eelpout embryos show suckling behaviour, and several individuals were found with the tip of the follicle within their oral cavity. If animals are merely placed in an overdose of anaesthetic, the escape response from the mother will cause all embryos to detach, and subsequent dissection will not reveal any embryos attached to follicles. From several approaches it would appear that a slow and careful approach is best. Pregnant individuals can be isolated in a suitable thermostatted container and allowed to settle down following handling. Once settled, anaesthetic is gradually introduced until fish lose equilibrium. Once fish lose equilibrium, they should be ventilated, but being careful when handling. Over the following hours the concentration of anaesthetic should be gradually increased, to reach a lethal dose within a few hours. With this approach it was always possible to observe 2-6 embryos (out of a maximum of 36) attached to follicles during dissection.

The follicle entered the oral cavity either via the operculum or directly through the mouth (Fig. 6A). From sagittal sections of the head from an individual in which the follicle enters by the mouth, it is apparent that only the outer $3-5 \mathrm{~mm}$ are engulfed (Fig. 6B). This corresponds to the region of the follicle containing the glomerulus, and the mouth is closed down on the follicle proximal to this structure. Positioned in this manner, the tip of the follicle reaches the opening to the oesophagus (Fig. 6B). 

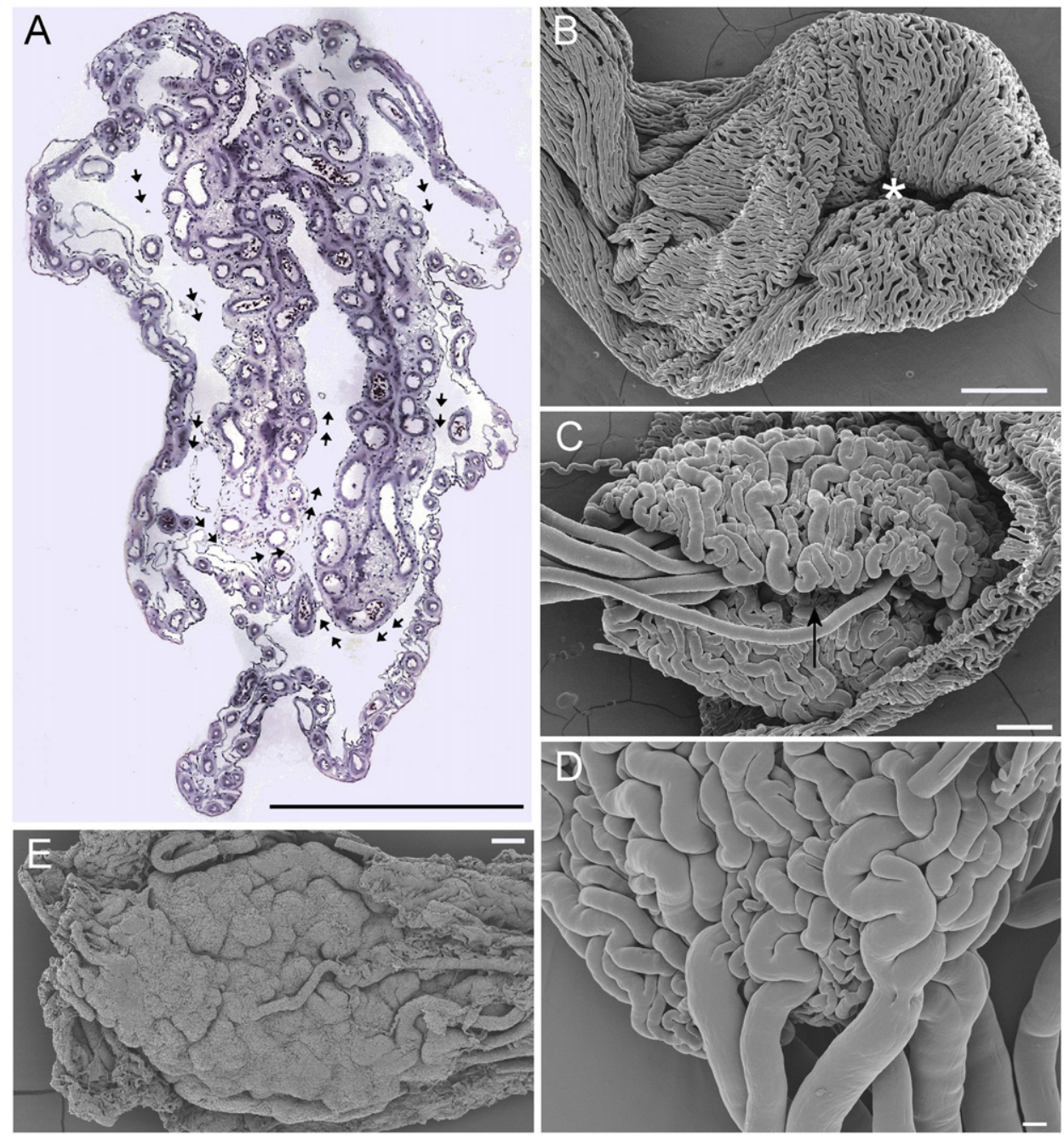

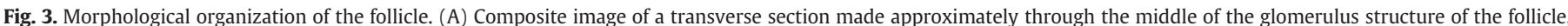

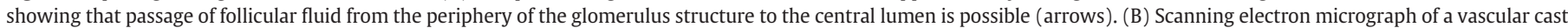

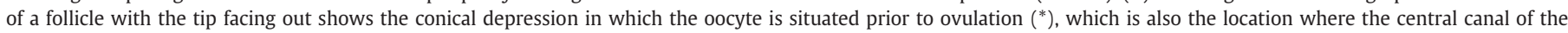

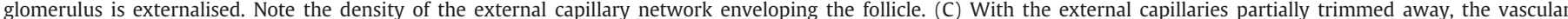

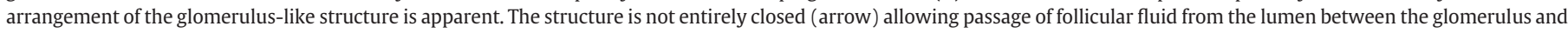

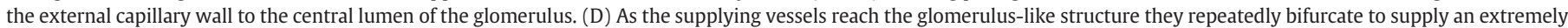

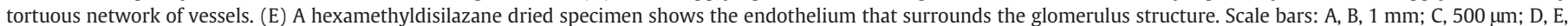
$100 \mu \mathrm{m}$

\section{Discussion}

The $32 \%$ increase in the resting metabolic rate of near-term females compared to non-reproductive males is in good agreement with previously published accounts on the metabolism of live-bearing fishes. In near-term females of rockfish Sebastes schlegeli oxygen consumption in near-term females was $68 \%$ higher than in nonreproductive males (Boehlert et al., 1991) and for S. flavidus this was $101 \%$ higher (Hopkins et al., 1995). Similar increases have been observed for the molly Poecilia latipinna (27\%) (Timmerman and Chapman, 2003), and surfperches Rhacochilus vacca and Embiotoca lateralis (53\%) (Webb and Brett, 1972). That mass specific metabolic rate scaled linearly with body mass is presumably an indicator that metabolic growth and organogenesis of the embryos are metabolically costly.

The metabolic oxygen requirement by a gestating female can be summarized as the sum of non-reproductive oxygen consumption, embryo oxygen consumption and oxygen requirement to maintain the litter (Timmerman and Chapman, 2003). Thus, for Z. viviparus, the metabolic cost associated with gestation can be approximated by subtracting the SMR of a non-reproductive individual; a $100 \mathrm{~g}$ near- term female with a SMR of $3.28 \mathrm{mg} \mathrm{O}_{2} \mathrm{~h}^{-1}$ (Eq. (4)), would weigh $71.6 \mathrm{~g}$ if she were non-reproductive and therefore have a SMR of $1.86 \mathrm{mg} \mathrm{O}_{2} \mathrm{~h}^{-1}$ (Eq. (5)). Therefore, the metabolic cost of litter maintenance and oxygen consumption by embryos, accounts for almost half (43\%) of the SMR of a near-term female.

The present results showed that the ovarian environment is far more hypoxic than previously assumed. Hartvig and Weber (1984) reported oxygen tensions in the ovary of $Z$. viviparus to be $\sim 5 \mathrm{kPa}$, but in the 4 individuals we examined, $\mathrm{PO}_{2}$ in the ovarian lumen rarely exceeded $0.5 \mathrm{kPa}$. A $\mathrm{PO}_{2}$ of $5 \mathrm{kPa}$ was only observed in the peripheral 3-4 mm, although immediately adjacent to the follicles, the ovarian fluid was fully oxygenated. Korsgaard (1994) reported a pH of 7.5 in the ovarian fluid, which is likely to be somewhat lower than maternal plasma, and this may provide sufficient Root effect to unload oxygen from the maternal blood during passage of the follicular vascular network. The oxygen profile of the ovary would suggest that embryos must remain in close proximity to the follicles to obtain sufficient oxygen. Even given the higher oxygen affinity of embryonic blood (Hartvig and Weber, 1984) embryonic haemoglobin could achieve no more than $20 \%$ saturation in the ovary lumen. It might be argued that the low oxygen pressures measured in the current study were an 

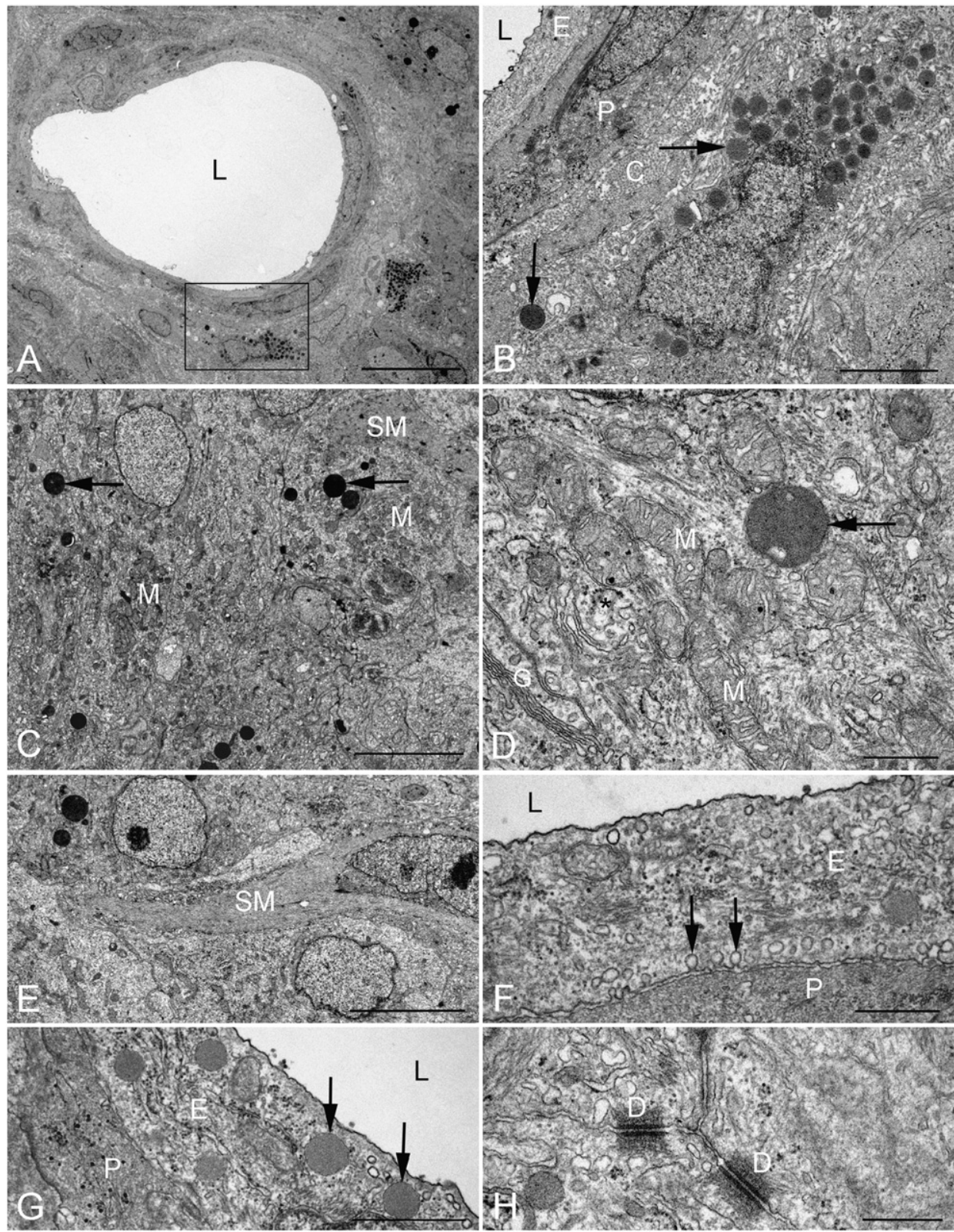

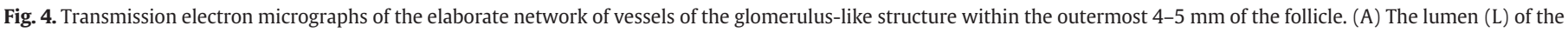

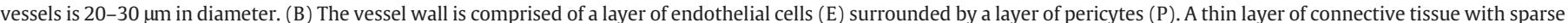

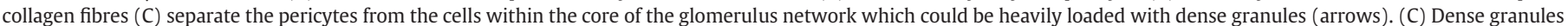

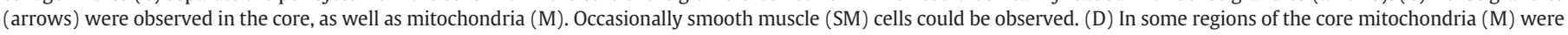

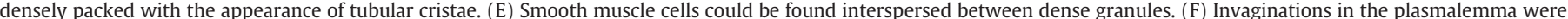

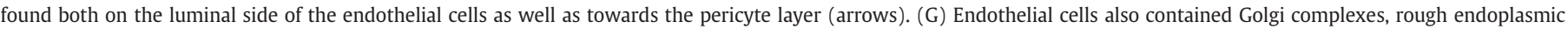

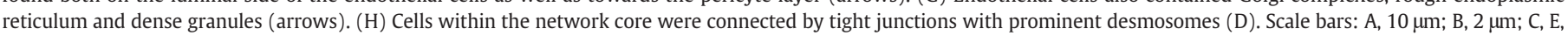
$5 \mu \mathrm{m} ; \mathrm{D}, \mathrm{F}, \mathrm{H}, 500 \mathrm{~nm} ; \mathrm{G} 1 \mu \mathrm{m}$.

artefact caused by reduced ovarian blood perfusion resulting from the anaesthesia. In our opinion, the high oxygen tensions measured adjacent to the follicles, including those located opposite to the entry site of the oxygen sensor, do not suggest this to be the case. Maintaining a juxtaposition of the follicle and the gills of the embryos also constitutes an energetic advantage in that the maternal organism does not have to expend large amounts of energy in maintaining high oxygen levels throughout the ovary. Embryos have a thick avascular epidermis making it unlikely that they lose oxygen to their environment across the body surface.

Viviparity has evolved on 132 independent occasions in the lower vertebrates; the vast majority of these being placental reptiles (72\%) or cartilaginous fishes (8\%) (Blackburn, 1992). Aplacental matro- trophic viviparity has evolved on 12 occasions in teleost fishes (Blackburn, 1992). To date, nutrients have been considered derived from the maternal circulation in all species, except the European eelpout. The present work shows that embryos of the eelpout obtain nutrients by suckling on ovarian follicles, and that these nutrients are also derived from the maternal circulation. The profiles from the gel electrophoresis support the suggestion that nutrients are passed directly from the follicle to the embryos without intermediary mixing in the ovarian fluid. The role of the mobile jaw apparatus is most likely to facilitate swallowing of fluid (Soin, 1968). However, we also believe it constitutes an anatomical requirement for suckling, both for the purpose of attachment to the follicle and for obtaining follicular fluid. The developmental stage at which the initial attachment of embryos 


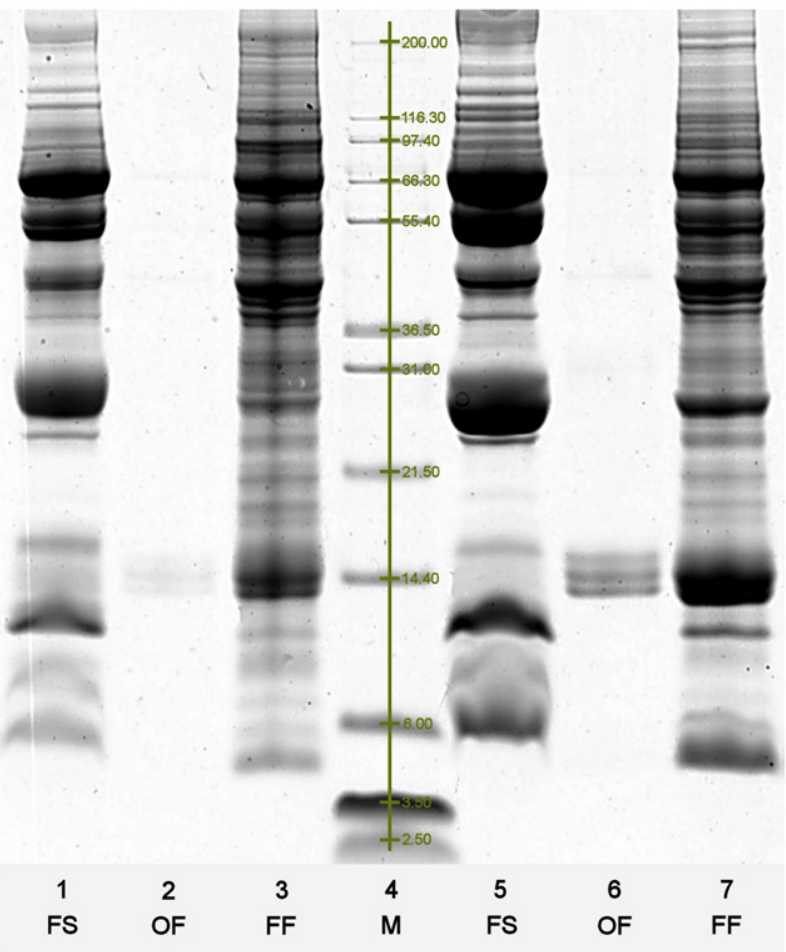

Fig. 5. SDS-PAGE protein separation of serum, ovarian fluid, and follicular fluid from near-term pregnant female. Lanes 1 and 5, female serum (FS); lanes 2 and 6, ovarian fluid (OF); lanes 3 and 7 follicular fluid (FF); lane 4, molecular markers (2.5-200 kDa).
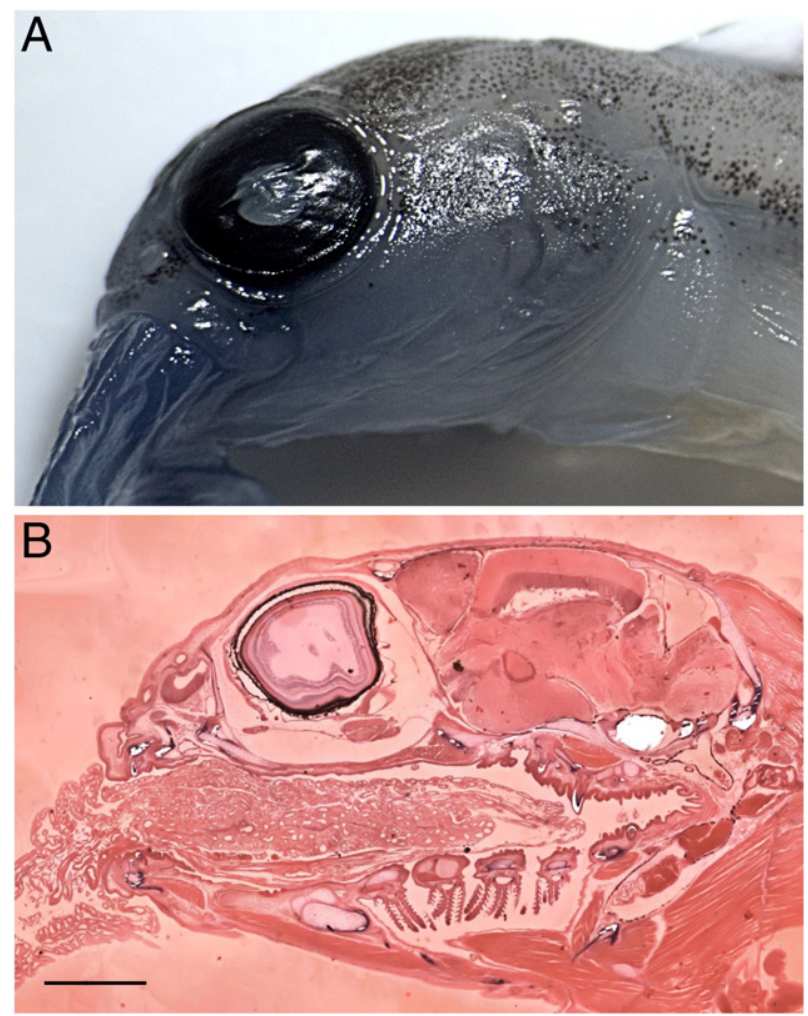

Fig. 6. Orientation of the follicle within the oral cavity of an embryo. (A) Light micrograph showing the follicle entering the oral cavity by way of the mouth in a nearterm embryo. (B) Composite light microscopy of a sagittal section showing the positioning within, in particular that only the region containing the glomerulus-like structure is engulfed. Scale bars $1 \mathrm{~mm}$. occur is unknown, but clearly not until embryos are of adequate size. Studies on embryonic development (Rasmussen et al., 2006) would suggest it to occur approximately 2 months after hatching, which also coincides with the depletion of the yolk sac (Rasmussen et al., 2006).

The glomerulus-like structure within the tip of the ovarian follicles has never previously been observed in $Z$. viviparus or any other livebearing species. This observation was only made possible by the use of a novel casting material which can be dissected following polymerization. Ultrastructural observations the blood vessels of the glomerulus and associated tissues reveal a highly specialized structure. The cells making up the mesangial-like core of the glomerulus contain numerous mitochondria. The clustered arrangement with tubular cristae is a feature characteristic of cells from the adrenal cortex and other steroid-synthesizing cells (Belt and Pease, 1956). Numerous electron dense granules, rough endoplasmic reticulum and Golgi complexes could also be observed, indicative of synthesizing capacity. Tight junctions and the absence of fenestrae between endothelial cells of the blood vessels imply that any potential synthesized products of the mesangial-like cells are not targeted for transport into the maternal blood. However, the endothelial cells contained numerous electron dense bodies, pinocytotic vesicles and caveolae, all indicative of potential transcellular transport functions. The finding that protein bands are present in the follicular fluid with a size fraction different from the maternal serum indicates either de novo synthesis, or a modification of protein derived from the maternal circulation, within the glomerulus. The function of the observed smooth muscle cells within the glomerulus is unclear. It may well serve a function of constricting the glomerulus to avoid protein-rich follicular fluid from seeping into the ovarian fluid during non-suckling periods.

At present, we have no knowledge of the nature, of non-nutritive substances that could potentially be synthesized in the glomerulus. When an organism is born, it is delivered into an environment rich in pathogens. It is generally accepted that a transfer of immunocompetence occurs from the maternal organism prior to parturition, also in fish (Swain and Nayak, 2009). Any role the follicles may serve in maternal immunity transfer in the eelpout deserves further attention.

Suckling behaviour has never previously been observed in $Z$. viviparus. The reason for this is probably that the attachment between embryo and follicle is not static. Embryos are easily disturbed when handling the female and detach from the follicles. Even with the utmost care, the dissection of fresh specimens has never allowed observations of embryos engaged in suckling. Admittedly it is difficult to ensure that embryos remain attached to the follicles during fixation, and when successful, it is only a few that do. There is nothing to suggest that embryos are permanently attached to the follicles; most probably they are able to detach and relocate at will. Following handling, pregnant females can subsequently be brought to spawn, implying that embryos are able to locate a vacant follicle following disturbances, yet the homing mechanisms responsible are unknown. Suckling is an efficient strategy for several reasons; one being that embryos receive concentrated nutrients rather than having to forage within the ovary. The presence of one follicle per embryo presumably also ensures an equal distribution of nutrients, and would account for the small variation in individual size at term (Rasmussen et al., 2006).

We have demonstrated a strong dependency between the eelpout embryo and the ovarian follicles, in which the latter serves a functional analogy to a combined placenta and teat during embryonic development. This bears some resemblance to the ovarian leaf-shaped projections in Jenynsia lineata described by Turner (1940). The morphological and functional specializations of the follicles lend evidence to a very complex matrotrophic relationship in Z. viviparus, with numerous physiological and behavioural adaptations. 


\section{Acknowledgements}

PVS was funded by the Carlsberg Foundation (Grant. no. 2006-010545). All material costs associated with the project were funded by the Elisabeth and Knud Petersen Foundation. [SS]

\section{References}

Balon, E.K., 1975. Reproductive guilds of fishes - proposal and definition. J. Fish. Res. Board Can. 32, 821-864

Belt, W.D., Pease, D.C., 1956. Mitochondrial structure in sites of steroid secretion. J. Biophys. Biochem. Cytol. Suppl. 2, 369-374.

Blackburn, D.G., 1992. Convergent evolution of viviparity, matrotrophy, and specializations for fetal nutrition in reptiles and other vertebrates. Am. Zool. 32, 313-321.

Boehlert, G.W., Kusakari, M., Yamada, J., 1991. Oxygen consumption of gestating female Sebastes schlegeli - estimating the reproductive costs of livebearing. Environ. Biol. Fishes 30, 81-89.

Braet, F., DeZanger, R., Wisse, E., 1997. Drying cells for SEM, AFM and TEM by hexamethyldisilazane: a study on hepatic endothelial cells. J. Microsc. Oxford 186, 84-87.

Hopkins, T.E., Eldridge, M.B., Cech, J.J., 1995. Metabolic costs of viviparity in yellowtail rockfish, Sebastes flavidus. Environ. Biol. Fishes 43, 77-84.

Hartvig, M., Weber, R.E., 1984. Blood adaptations for maternal-fetal oxygen transfer in the viviparous teleost, Zoarces viviparus L.. In: Seymour, R. (Ed.), Respiration and Metabolism of Embryonic Vertebrates. Dr W Junk Publishers, Dordrecht, pp. 17-30

Jollie, W.P., Jollie, L.G. 1964. Fine structure of ovarian follicle of ovoviviparous Poeciliid fish Lebistes reticulates. 2. Formation of follicular pseudoplacenta. J. Morphol. 114, 503-525.

Korsgaard, B., 1983. The chemical composition of follicular and ovarian fluids of the pregnant blenny (Zoarces viviparus (L.)). Can. J. Zool. 61, 1101-1108.

Korsgaard, B., 1994. Nitrogen distribution and excretion during embryonic post-yolk sac development in Zoarces viviparus. J. Comp. Physiol. 164, 42-46.
Korsgaard, B., Andersen, F.O., 1985. Embryonic nutrition, growth and energetics in Zoarces viviparus as indication of a maternal-fetal trophic relationship. J. Comp. Physiol. 155, 437-444.

Kristoffersson, R., Broberg, S., Pekkarinen, M., 1973. Histology and physiology of embryotrophe formation, embryonic nutrition and growth in the eel-pout, Zoarces viviparus (L.). Ann. Zool. Fennici 10, 467-477.

Rasmussen, T.H., Jespersen, A., Korsgaard, B., 2006. Gonadal morphogenesis and sex differentiation in intraovarian embryos of the viviparous fish Zoarces viviparus (Teleostei, Perciformes, Zoarcidae): a histological and ultrastructural study. J. Morphol. 267, 1032-1047.

Skov, P.V., Bennett, M.B., 2004. The secondary vascular system of Actinopterygii: interspecific variation in origins and investment. Zoomorph. 123, 55-64.

Skov, P.V., Sorensen, T.F., Ramlov, H., Steffensen, J.F., 2007. Vascular arrangement and ultrastructure of the European eelpout Zoarces viviparus ovary: implications for maternal-embryonic exchange. Anat. Rec. 290, 1500-1507.

Soin, S.G., 1968. Some features in the development of the blenny [Zoarces viviparus (L.)] in relation to viviparity. Probl. Ichthyol. 8, 222-229.

Steffensen, J.F., 1989. Some errors in respirometry of aquatic breathers - how to avoid and correct for them. Fish Physiol. Biochem. 6, 49-59.

Steffensen, J.F., Schurmann, H., Bushnell, P.G., 1994. Oxygen-consumption in 4 species of teleosts from Greenland - no evidence of metabolic cold adaptation. Polar Biol. $14,49-54$

Stuhlmann, F., 1887. Zur kenntnis des Ovariums der Aalmutter (Zoarces viviparus Cuv.). Abhandling aus dem Gebiet der Naturwissenschaften 10, 3-48.

Swain, P., Nayak, S.K., 2009. Role of maternally derived immunity in fish. Fish Shellfish Immunol. 27, 89-99.

Timmerman, C.M., Chapman, L.J., 2003. The effect of gestational state on oxygen consumption and response to hypoxia in the sailfin molly, Poecilia latipinna. Environ. Biol. Fishes 68, 293-299.

Turner, C.L., 1940. Adaptions for viviparity in jenynsiid fishes. J. Morphol. 67, 291-297.

Turner, C.L., 1947. Viviparity in teleost fishes. Sci. Mon. 65, 508-518.

Webb, P.W., Brett, J.R., 1972. Respiratory adaptations of prenatal young in ovary of 2 species of viviparous seaperch, Rhacochilus vacca and Embiotoca lateralis. J. Fish. Res. Board Can. 29, 1525-1542. 